\title{
An Interactive Approach to Contraception Teaching Amongst Medical Undergraduates
}

\author{
Arasoo, V.J.T., Dominic, N.A., Ratnasingam, V., Ismail, R.Z.R., Mahadavan, J.V.D., Sood, M. \& \\ Kumar, $A$.
}

\begin{abstract}
Contraception is an essential requirement for most women in the reproductive age group. This paper describes an interactive learning programme called Advancing Contraception Teaching (ACT) intended to increase knowledge and better foster workforce readiness amongst medical graduates. It was evaluated by a single-arm pre and follow-up post-test study design and feedback analysis. The Wilcoxon signed-rank test showed that the median of differences between the pre-test knowledge and post-test knowledge scores was significantly different $(p<.001)$ and feedback was largely positive. The ACT programme is an effective interactive method of teaching contraception to medical undergraduates, demonstrating a positive learning gradient and an improved learning experience. It can be transformed into a remote learning programme with contact time required only for the hands-on section. It can also be used as a training module for junior doctors not exposed to a comprehensive undergraduate contraception teaching module.
\end{abstract}

Keywords: Contraception teaching, Evaluation, Interactive, Undergraduate, Work-force readiness

\section{Introduction}

Contraception is a fundamental primary care right of women in the reproductive age group. This is relevant in the current global social environment, where increasingly early exposure to sexual encounters escalates the risk of unwanted pregnancies and sexually transmitted infections (STIs). Data from the United Nations Global perspective showed an estimated 33 million pregnancies worldwide were unintended (United Nations, 2015). A study published in Lancet Global Health showed that between 2010-14 a worldwide estimation of $44 \%$ of pregnancies were unintended (Bearak, et al., 2018). Unsafe sex has been identified by the World Health Organisation as the second most risk factor for disease disability and death in the lowerincome countries and the ninth in the higherincome countries. Unintended pregnancies and STIs are negative consequences of unsafe sex, hence the need for effective contraception education.

Monash University, Malaysia.

Corresponding Author: Dr Valliammai Jayanthi Thirunavuk Arasoo, Monash University, Malaysia.

Email: t.jayanthi@monash.edu
It is important to ensure that physicians are competent in advising on available methods of contraception. They are integral to improving sexual and reproductive health, thus reducing rates of unwanted pregnancies and unsafe terminations. Approximately $90 \%$ of women rely on physicians' advice to make contraceptives choices (ESHRE Capri Workshop Group, 2014). Hence, medical education must facilitate professionals to become clinically competent and develop critical thinking to provide evidence-based contraceptive options and counselling.

This paper describes an interactive learning programme called Advancing Contraception Teaching (ACT) intended to ensure that future clinicians are knowledgeable and confident of providing contraceptive options. Interactive learning here combines traditional lecture with active student participation in question-andanswer sessions, curated stations enabling students to work with each other and the instructor to enhance learning and finally learning practical skills on simulators. This study is based in Malaysia where unintended pregnancies and baby abandonment rates are high (The Star, 2018). In the National Health and Morbidity 2017 survey of students (aged $13-17$ years), $7.3 \%$ of Malaysian students said they have had sex before. Among these students, only $22 \%$ used any form of 
contraception (Institute of Public Health, 2018). A Malaysian study showed $42.9 \%$ of pregnancies were unplanned, with the highest prevalence amongst older Muslim women (Yusof, et al., 2018). The contraceptive prevalence rate in Malaysia for modern methods was about $40 \%$ with an existing gap of unmet needs up to $18 \%$ (United Nations, 2017). This may indicate the glaring disparity between the obvious need for counselling and adequate contraceptive provision and the lack of it.

The ACT programme is based on the pedagogical concept of active learning, where students participate and interact with the learning process, as opposed to a passive flow of information from tutor to student. Combining workshop-style learning with didactic teaching is known to be more effective than traditional didactic lectures alone (Satterlee, et al., 2008). To date, there are a limited number of studies looking into the effectiveness of using blended or interactive methods to teach contraception.

This is an innovative, comprehensive and interactive method of teaching contraception to medical undergraduates that is easily replicable by other medical schools and can be used to better prepare junior doctors with no prior exposure to a comprehensive contraception module.

\section{Methods}

This project evaluation was assessed by the Monash University Human Research Ethics Committee (MUHREC - 18344) to be a quality assurance project and was considered suitable for verbal consent.

This study aimed to evaluate the impact of the ACT programme on medical students' knowledge and learning experience. This pretest and follow-up post-test single-arm study was conducted at Monash University Malaysia from February to May 2019. All 120 fourth-year students enrolled in the five-year Doctor of Medicine course were invited to attend the ACT programme during their General Practice and Women's Health rotation.

The students were reassured that test scores would not affect their summative assessment for the MD course. Participation in the research was voluntary; students could participate in the ACT programme but decline participation in the evaluation. Students undergoing General Practice or Women's Health rotations in the same semester were recruited at the start of the rotation to ensure no prior exposure to contraception teaching. Being a single-arm prepost-study meant that the participating students were the study controls as the pretest assessed their knowledge before the intervention. The follow-up post-test to evaluate the effectiveness of the ACT programme was conducted 2 weeks later to mitigate short-term recall.

The ACT programme was structured such that the pre-reading material was provided two weeks before the intervention to encourage preparation. The intervention started with a pretest that was followed by a lecture, with the opportunity for students to clarify any discrepancies in their knowledge and understanding of the subject. The workshop was conducted with 30 students in each session who were then subdivided into 6 students per group. They rotated every 20 minutes through five stations. Students were offered a paper-based evaluation survey upon completion of the workshop. A four-domain questionnaire and an open-ended question were used to evaluate the students' learning experience.

\subsection{Pre-test and Post-test Content}

The team of tutors from General Practice and Women's Health created 12 Multiple Choice Questions (MCQ) that tested students' knowledge of various contraceptive methods based on the curriculum. Each question had 5 branches that carried equal weightage of 1 mark each. No marks were deducted for wrong answers. The maximum marks achievable was 60 . Both the pre-tests and post-tests used the same MCQs but the order was rearranged in the post-test.

\subsection{Workshop overview}

The workshop was divided into 5 stations covering components of contraception training, as depicted in Table 1. Each station was approached using case scenarios which facilitated clinical reasoning and counselling skills. In the long-acting reversible contraceptives stations, students were shown and allowed to practice insertions and removals of intrauterine contraceptive devices (IUCDs) and subdermal implants on simulators.

The stations are as described in Table 1. 
Table 1: Content incorporated into interactive stations

\begin{tabular}{lccll}
\hline $\begin{array}{l}\text { Contraceptive } \\
\text { Method }\end{array}$ & $\begin{array}{l}\text { Clinical } \\
\text { Reasoning } \\
\text { Oral contraceptives }\end{array}$ & $\begin{array}{l}\text { Counselling } \\
\text { Skills }\end{array}$ & $\begin{array}{l}\text { Hands-on } \\
\text { practice }\end{array}$ & $\begin{array}{l}\text { Others } \\
\text { Review of OCP samples }\end{array}$ \\
\hline Injectables \& Barrier & $\checkmark$ & $\checkmark$ & $\begin{array}{l}\text { Review of barrier } \\
\text { samples }\end{array}$ \\
\hline IUCD & $\checkmark$ & $\checkmark$ & $\checkmark$ & \\
\hline Subdermal Implants & $\checkmark$ & $\checkmark$ & $\checkmark$ & $\begin{array}{l}\text { Video of laparoscopic } \\
\text { tubal ligation }\end{array}$ \\
\hline Sterilisation & $\checkmark$ & $\checkmark$ & & \\
\hline
\end{tabular}

\subsubsection{Oral Contraceptives}

The combined hormonal station was conducted by a thorough discussion based on given scenarios. The discussion involved the initial assessment (history and examination) of patients requesting contraception. The students were introduced to Medical Eligibility Criteria (MEC) for contraception. They were asked to refer to the MEC and look for suitable contraception for women with various medical conditions. Further discussion took place on the various types of oral contraceptives (how to start, what to do if missed pills/delayed administration of patch or vaginal ring, potential side effects). The final part of the discussion was about Gillick's competence and Fraser guidelines which were based on the scenario of an underage girl requesting contraception.

\subsubsection{Injectables and Barrier contraceptives}

This station was conducted based on the contraceptive needs of three different scenarios. The first scenario was for a migrant of low socio-economic status, the second was for a perimenopausal woman and the third dealt with postpartum contraception advice. In all the scenarios, discussions not only looked into contraceptive advice but also the prevention of STIs and other risk factors that were noted in each scenario.

\subsubsection{Intrauterine Contraceptive Device Contraceptive (IUCD)}

In this station, students were initially quizzed on the risks and benefits of the IUCD and patient suitability. They were then shown the various instruments used in the process of an IUCD insertion, including a Cusco's speculum, sponge forceps, uterine sound, tenaculum or Vulsellum and a few different IUCD's, e.g. Mona Lisa Cu 375 and the Mirena.
The tutor then demonstrated a step-by-step insertion and removal of IUCD. The pelvic models used for this station allow the actual insertion and removal of the IUCD. The students then individually performed the procedure under supervision.

\subsubsection{Subdermal Implants}

Summarised reading material was used during the discussion to consolidate understanding of subdermal implants. This was followed by a demonstration of subdermal implant insertion and removal on arm models. The students practised as teams of two where they demonstrated counselling for one who opts for the device. They then attempted inserting and removing the implant under supervision.

\subsubsection{Sterilization}

Students viewed a short video clip on laparoscopic tubal ligation. This was followed by a robust discussion on counselling patients for tubal ligation and vasectomy. The tutor facilitating the station acted as the simulated patient. Two case scenarios were discussed. The first case was an obese diabetic woman wanting tubal ligation. The option of a vasectomy for her healthy spouse was explored. The second involved counselling a multipara wanting tubal ligation.

\subsection{Data Collection}

The follow-up post-test was held two weeks after the workshop. Only pre-test and post-test submissions that could be matched were included in the quantitative analysis. Students' performance was reported using frequency statistics. The IBM SPSS software (programme version 24, ARMONK, NY) was used to analyse the collected data. Paired t-test was used to analyse the difference between the mean scores of the pre-tests and post-tests. A student 
evaluation form, with four specific questions assessing the usefulness of the programme and a section to provide feedback, was offered at the end of the workshop.

\section{Results}

Post-tests scores showed a significant improvement from that of the pre-test. Students also evaluated the usefulness of the programme positively.

\subsection{Quantitative analysis}

\subsubsection{Pre-test and Post-test results}

Out of the 120 students who participated in the workshop, 115 students attempted the pre-test and 77 students attempted the post-test. The pre-test participation was higher as it was administered as part of the overview lecture whereas the post-test was administered after a two-week interval. Only submissions of those who had completed both the pre- and post-tests were analysed. There were also incomplete submissions which disabled the matching of pre- and post-test scores. This reduced the number to 69 . The median Interquartile Range (IQR) of the pre-test and post-test knowledge scores ( $n=69)$ were 29.0 (IQR: $24.0-31.5)$ and 34.0 (IQRbm: 31.5 - 36.0) respectively. The Wilcoxon signed-rank test showed that the median of differences between the pre-test knowledge and post-test knowledge scores (median change in score of 4.0 (IQR: 0.5 10.0)) was significant $(p<.001)$.

\subsubsection{Student satisfaction of learning} contraception through the ACT programme

A total of 93 students (77.5\%) responded to the questionnaire immediately after the workshop, using Likert scale responses $(1=$ strongly disagree, $2=$ disagree, $3=$ neutral, $4=$ agree, $5=$ strongly agree) to the four questions evaluating the usefulness of the workshop. Mean scores and standard deviations were calculated for each question (Table 2). The mean scores for each statement were all greater than 4 , which indicates that the students demonstrated a positive perception about the usefulness of the programme.

Table 2: Student Evaluation on Usefulness of ACT Programme

\begin{tabular}{lll}
\hline EVALUATION QUESTIONS (N=93) & MEAN & STD DEVIATION \\
\hline $\begin{array}{l}\text { Q1. THE SESSION PROVIDED A HOLISTIC AND INTEGRATED } \\
\text { APPROACH TO PATIENT CARE AND MANAGEMENT. }\end{array}$ & 4.57 & 0.813 \\
\hline $\begin{array}{l}\text { Q2. THE TEACHING SESSION MATERIALS AND RESOURCES WERE } \\
\text { HELPFUL IN THE LEARNING NEEDS. }\end{array}$ & 4.53 & 0.855 \\
\hline $\begin{array}{l}\text { Q3. THE SESSION HELPED IN IMPROVING MY KNOWLEDGE AND } \\
\text { LEARNING OUTCOMES. }\end{array}$ & 4.57 & 0.813 \\
\hline $\begin{array}{l}\text { Q4.THE SESSIONS CONDUCTED BY THE FACILITATORS WERE } \\
\text { INTERACTIVE AND ENGAGING. }\end{array}$ & 4.66 & 0.787 \\
\hline
\end{tabular}

\subsection{Feedback Analysis}

Three assessors were responsible for critically evaluating the feedback to minimise the researcher bias. Conventional content analysis was performed on the open-ended feedback section of students' overall thoughts of the ACT programme excluding the post-test as it was held 2 weeks after the workshop. The openended feedback section generated responses from 71 students. Some gave more than one response. These were analysed and categorised into two main categories of "appreciative" and "critical", and then further subdivided into themes. The six key themes that emerged from the feedback received is detailed in Table 3.

The majority of students perceived the workshop as a positive learning experience. Some students expressed their appreciation of the interactive nature of this session and hoped more of such workshops could be done on other topics. 
Table 3: Feedback Categories and Themes

\begin{tabular}{|l|l|c|}
\hline \multirow{2}{*}{$\begin{array}{l}\text { Category } \\
\text { Appreciative }\end{array}$} & \multicolumn{1}{|c|}{ Theme } & No of responses \\
& $\begin{array}{l}\text { Valued the workshop } \\
\text { Effective teaching based on case scenarios }\end{array}$ & 48 \\
\hline & Request for similar workshops on other topics & 5 \\
\hline Critical & Engagement throughout the interactive session & 6 \\
\hline & Excessive reading material was not helpful & 5 \\
\cline { 2 - 3 } & Duration of the interactive session was too short & 12 \\
\hline
\end{tabular}

"Provided an overview to students. A good guide for us to have a basic understanding prior to deeper learning."

"Great session, extremely helpful to have so many tutors in one place for us to ask questions and learn."

\section{"Very good interactive session."}

\section{Scenario-based teaching}

Students felt that the scenario-based teaching session encouraged them to integrate their knowledge into clinical practice.

"Very well organized workshop. Case based approach helps to relate theoretical knowledge to clinical practice."

"The format of the workshop, the lecture prior to it, everything from start-end was arranged quite well. The consolidation of the theory into stations with scenarios has proven to be very effective in the learning process, also in remembering facts and the theory behind. It would be great if we could have more workshops like this on different topics every week, would be incredibly helpful for us."

\section{Duration}

Several students felt that the 20-minute duration for each station was inadequate and, as a result, stations that covered more material were a bit rushed.

"The stations were more kind of a rush, maybe extra 5 minutes would help. Overall well executed."

"This year's workshop is much more useful as it is more Interactive with plenty of scenarios. Room for improvement is on timing, I believe 30 minutes per station would be more beneficial, if not 25 minutes."

\section{Reading materials}

While the students generally appreciated the workshop, some students criticised the prereading material materials given to them. They expressed their preference for more condensed and comprehensive notes.

"Workshop is helpful in consolidating information. Reading material had too many articles to read, would prefer more comprehensive \& consolidated reading materials. Time for teaching station is just nice."

\section{Discussion}

This paper describes an innovative educational practice of teaching contraception to medical undergraduates. It evaluates the students' learning experience in the ACT programme using pre-test and post-test methods and feedback analysis. In this study, innovations were made from the traditional lecture-based teaching on contraception at our university. We provided pre-reading material two weeks before the pre-test so that students have background knowledge before attempting the pre-test. The active session then enhances and strengthens the previously acquired knowledge. Incorporating communication and clinical reasoning skills into the case scenarios and hands-on procedures/simulation further augments the learning experience as students can critically analyse case scenarios and plan a holistic comprehensive management. This helped with the retention of the knowledge gained. Although it was only a $17 \%$ improvement over the baseline score, the follow-up post-test conducted two weeks after the intervention showed significant statistical evidence of improvement in knowledge. This suggests that the ACT programme improved the students' performance in the MCQ test on 
the assessment of contraception. Counselling skills could not be assessed by the MCQs but the facilitators ensured that every student participated in the active session. They learned not only from participating and observing their peers but also from feedback given immediately. Although Problem Based Learning (PBL) and Simulation are used extensively by medical schools in Malaysia, active participation by facilitators might not be present. In a study conducted by a Malaysian medical school, students lamented the lack of interaction with the facilitators and some students dominating discussions while others remained passive (Barman, et al., 2006).

The feedback on the effectiveness of the programme showed significant mean scores for each statement with all greater than 4 (on a scale of 1 to 5), indicating that the students had a positive perception about the usefulness of the programme.

Traditional teaching methods were didactic and limited to a single discipline. In more recent years, medical schools have incorporated case discussions and PBL, with some element of handling contraceptive devices. There are limited reports on a comprehensive learning modality like ours. We integrated Women's Health with General Practice to consolidate learning of contraception, thus enabling students to apply the skills acquired in both primary care and gynaecology settings.

The ACT programme consisted of an overview introductory lecture followed by the interactive workshop, hence making it a comprehensive approach to learning contraception. Increasingly, lecture-style teaching is being abandoned in favour of interactive workshops to promote student engagement. However, a multinational study on resident emergency physicians in four Asian hospitals showed that those who attended the lecture sessions followed by the clinical skills simulation performed better than those who did it in reverse. They opined that the didactic lectures equipped the participants with the background knowledge required to understand the clinical simulations better (Li, et al., 2012).

Interactive workshops add value to the learning experience of undergraduate students. The format of integrating a clinical case and relating that to theoretical knowledge proved to be an effective learning process. Our interactive workshop employed a more comprehensive strategy compared to a team which studied standard lectures with interactive lectures on contraception. Both groups were given handbooks on contraception and attended lectures. Those in the interactive lectures group were additionally given 2-4 questions to think about and present their answers during the interactive lectures. However, no statistical difference in pre-test versus post-test scores was recorded (Cwiak, et al., 2004).

An option of teaching contraception can be through team-based learning where small groups discussed the given topic before presentation. The ACT programme was curated to explore self-study followed by consolidation of learned materials through group discussion at the counselling sections of the various stations. The post-test showed significant improvement in scores although it was held two weeks after the workshop to negate short-term recall. Student feedback was also positive. Mody et al. (2013) explored compared team-based learning against traditional lectures. Students in team-based learning had curated pre-reading material as well as small group discussions before participating in mini-presentations of various contraceptive topics. Although there was no statistical significance in score improvements of pre-tests and post-tests between the groups, students in the team-based learning reported higher satisfaction scores (Mody, et al., 2013). A similar study conducted in Ethiopia also compared conventional didactic lectures on contraception to one that had added simulated sessions. The students in the intervention group had additional hour-long tutorials and seminars with simulated sessions on IUCD and implant insertions and removals. The intervention group demonstrated higher knowledge scores and were more skilled in both IUCD and Implant insertion and removal (Gebremeskel, et al., 2018).

The ACT programme explored counselling as a form of consolidating students' understanding of the subject. Students found the session beneficial. Students who opt for an Obstetrics \& Gynaecology rotation in Year 5 have the opportunity to attend a contraceptive clinic session to observe how patients are counselled on various methods of suitable contraceptives. This is in line with Swamy et al who opined that learning actively in a clinically realistic environment may promote the retrieval of the information in future clinical practice (Swamy, et al., 2013).

\section{Limitations of the study}

The limitations of this study are as follows. It was not done in a clinical setting to reflect readiness to practice as this study was 
conducted on medical undergraduates. There was also no pre-post control group comparing didactic session teaching to the comprehensive ACT programme. Furthermore, not all students completed the pre and post-tests as it was not compulsory to do so.

\section{Conclusion}

Contraception counselling is a skill that requires not only knowledge of all the available methods but also utilises clinical reasoning to select the most effective and appropriate contraceptive method for patients. This study demonstrates that effective interactive teaching of contraception helps to increase students' ability to do so. However, we need to refine the amount of pre-reading material given and increase the time spent on individual stations to enhance the ACT programme. It is also simple enough to be transformed into a remote learning programme with contact time required only for practicing device insertions. It can be utilised to teach junior doctors who did not have prior exposure to a comprehensive contraception module.

\section{Abbreviations}

ACT - Advancing Contraception teaching IUCD - Intrauterine Contraceptive Device IQR - Interquartile range

MCQ - Multiple Choice Questions

MEC - Medical Eligibility Criteria

OCP - Oral Contraceptive Pill

\section{Declarations}

\section{Ethics approval and consent to participate}

This project evaluation was assessed by the Monash University Human Research Ethics Committee (MUHREC - 18344) to be a quality assurance project and was considered suitable for verbal consent.

\section{Consent for publication}

Not applicable

\section{Availability of data and material}

The data that support the findings of this study are available from Monash University, Malaysia but restrictions apply to the availability of these data due to student confidentiality. Data is, however, available from the authors upon reasonable request that does not compromise student confidentiality.

\section{Competing Interest}

All authors do not have any conflicts of interest or commercial affiliations. MSD(Malaysia) provided sample subdermal implants and Johor Family Health Association provided the oral contraceptive pills, condoms and intrauterine devices with the understanding that this was purely for training purposes.

\section{Acknowledgement}

The team of authors would like to thank $A / P$ Suneet Sood, A/P Paul Fullerton, Dr Jeevitha Mariapun, Ms Nirmala Veerayah, Ms Heamaa Gunasegaran, Mr Abisina Bujang Saili and Mr Sanjay Raj Gunaravi for their assistance in this project.

\section{References}

Barman, A., Jaafar, R. and Naing, N. (2006). Perception of students about the problembased learning sessions conducted for medical and dental schools' students of Universiti Sains Malaysia. Education for Health, 19(3), pp. 363-368.

Bearak, J., Popinchalk, A., Alkema, L. \& Sedgh, G. (2018). Global, regional, and subregional trends in unintended pregnancy and its outcomes from 1990 to 2014: estimates from a Bayesian hierarchical model. The Lancet Global Health, 6(4), pp. 380-389. Doi:10.1016/S2214-109X(18)30029-9

Cwiak, C. A. et al. (2004). Teaching contraception: An interactive presentation using Managing Contraception. American Journal of Obstetrics and Gynaecology, 191(5), pp. 1788-1792. Doi: https://doi.org/10.1016/i.ajog.2004.07.065

ESHRE Capri Workshop Group (2014). Simultaneous prevention of unintended pregnancy and STIs: a challenging compromise. Human Reproduction Update, 20(6), pp. 952-963.

Evers, J., Farley, T., Gemzel-Danielson, K. \& Glasier, A. (2014). Simultaneous prevention of unintended pregnancy and STIs: a challenging compromise. Human Reproduction Update, 20(6), pp. 952-963.

Gebremeskel, B. G. et al. (2018). Structured integration of family planning curriculum: comparative assessment of knowledge and skills among new medical graduates in Ethiopia. Contraception, 98(2), pp. 89-94. Doi:10.1016/j.contraception.2018.04.001

Institute of Public Health (2018). NATIONAL HEALTH AND MORBIDITY SURVEY 
(NHMS) 2017. [Online] Available at: http://iku.moh.gov.my/images/IKU/Docume nt/REPORT/NHMS2017/NHMS2017/nfogra phic.pdf [Accessed 4 September 2020].

Li, C.-H.et al. (2012). A multinational randomised study comparing didactic lectures with case scenario in a severe sepsis medical simulation course. Emergency Medicine Journal, 29(7), pp. 559-564. Doi: 10.1136/emermed-2011$\underline{200068}$

Mody, S. K. et al. (2013). Team-based learning: a novel approach to medical student education in family planning. Contraception, 88(2), pp. 239-242. Doi: https://doi.org/10.1016/i.contraception.2012 .07 .012

Satterlee, W. G., Eggers, R. G. \& Grimes, D. A. (2008). Effective medical education: insights from the Cochrane Library. Obstetrical \& Gynecological Survey, 63(5), pp. 329-333. Doi: 10.1097/OGX.0b013e31816ff661

Swamy, M. et al. (2013). Role of SimMan in teaching clinical skills to preclinical medical students. BMC Medical Education, 13(20). Doi:10.1186/1472-6920-13-20
The Star (2018). 911 babies dumped since 2010. [Online] Available at: https://www.thestar.com.my/news/nation/20 18/10/23/911-babies-dumped-since-2010nearly-a-third-of-the-abandoned-infantshave-died-says-deputy-minister [Accessed 4 September 2020].

United Nations (2015). Trends in Contraceptive Use Worldwide. [Online] Available at: https://www.un.org/en/development/desa/p opulation/publications/pdf/family/trendsCont raceptiveUse2015Report.pdf [Accessed 4 September 2020].

United Nations (2017). World Family Planning [Highlights]. [Online] Available at: https://www.un.org/en/development/desa/p opulation/publications/pdf/family/WFP2017 Highlights.pdf [Accessed 4 September 2020].

Yusof, M., Samad, A. A., Omar, M. \& Ahmad, N. A. (2018). Unplanned Pregnancy and Its Associated Factors. Global Journal of Health Science, 10(8), pp. 132-142. Doi: 10.5539/gihs.v10n8p132 